\title{
Platelets-to-lymphocyte ratio and esophageal cancer
}

\author{
Antonios Athanasiou ${ }^{1}$, Michael Spartalis ${ }^{2}$, Eleftherios Spartalis ${ }^{2}$ \\ ${ }^{1}$ Department of Upper Gastrointestinal Surgery, University Hospitals Birmingham NHS Foundation Trust, Birmingham, UK; ${ }^{2}$ Laboratory of \\ Experimental Surgery and Surgical Research, University of Athens, Medical School, Athens, Greece \\ Correspondence to: Mr. Antonios Athanasiou. Department of Upper Gastrointestinal Surgery, University Hospitals Birmingham NHS Foundation \\ Trust, Mindelsohn Way, Edgbaston, Birmingham, UK. Email: antwnis_athanasiou@hotmail.com. \\ Response to: Deng J, Zhang P, Sun Y, et al. Prognostic and clinicopathological significance of platelet to lymphocyte ratio in esophageal cancer: a meta- \\ analysis. J Thorac Dis 2018;10:1522-31.
}

Submitted May 18, 2018. Accepted for publication Jul 06, 2018.

doi: $10.21037 /$ jtd.2018.07.41

View this article at: http://dx.doi.org/10.21037/jtd.2018.07.41

\section{Dear Editor,}

We read with great interest the recent publication by Deng et al. (1) published in the March 2018 issue of Fournal of Thoracic Disease. The authors have performed a meta-analysis in order to examine the role of platelet to lymphocyte ratio (PLR) in the prognosis of esophageal cancer and also to evaluate the relationship with tumor pathological characteristics. Thirteen articles with 4,621 patients from 2013 to 2017 were included in the metaanalysis. The pooled hazard ratios revealed that a high PLR was associated with poor survival of esophageal cancer. This is a very interesting meta-analysis in our understanding regarding the establishment of an important biomarker with significant prognostic ability in patients with esophageal cancer. Nevertheless, before the results of this meta-analysis achieve wider uptake, a few points should be taken into consideration. It is well known that in a meta-analysis the interpretation of the results of included studies are analysed by advanced mathematical models in order to calculate a common pooled effect precisely. As a result, the conclusions of a meta-analysis are directly proportional with the quality of the included studies (2). The aforementioned metaanalysis included studies with different design, making the conclusions controversial.

To begin with, there is a significant heterogeneity in the studies that the authors decided to include in their meta-analysis. Mainly, regarding the treatment methods (surgery, chemotherapy or chemo-radiotherapy), definition of outcomes after treatment (complete response or partial remission), timing of intervention, neoadjuvant or plus adjuvant treatment, stage of disease and demographic differences. Moreover, we noticed significant heterogeneity regarding the analysis of the relationship between lymph node metastasis (yes vs. no) and PLR $\left(\mathrm{I}^{2}=17.9\right)$, the association between TNM stage (stage III/IV vs. I/II) and PLR $\left(I^{2}=29.6\right)$, and the correlation between tumor length $(>3$ vs. $3 \mathrm{~cm})$ and PLR $\left(\mathrm{I}^{2}=12.3\right)$. The above important heterogeneity reduces the statistical power due to the fact that the included studies have widely varying outcomes (3).

Furthermore, according to our recent search of the literature, we confronted with 7 additional studies which should have been included in this meta-analysis due to the fact that they meet the inclusion and exclusion criteria (4-10). Table 1 demonstrates the characteristics of the studies that Deng et al. (1) have not included in their metaanalysis. More specifically, the aforementioned studies include 1,830 patients, published from 2011 to 2016 and were retrospectively designed. Five studies were from China and two from the UK. The cut-off points for the PLR ranged from 103 to 300 while six studies included patients with esophageal squamous cell carcinoma (SCC) and four with adenocarcinoma (ADC).

We suggest that Deng et al. (1) should repeat their metaanalysis including the additional seven studies that we suggest in order to analyse a larger group with additional 1,830 patients. Last but not least, the results of this study could be significantly more reliable if Deng et al. (1) include additional data regarding the publication bias. 
Table 1 Main characteristics of the additional studies

\begin{tabular}{|c|c|c|c|c|c|c|c|c|c|c|c|}
\hline Study & Year & Country & $\begin{array}{l}\text { Age (mean or } \\
\text { median) }\end{array}$ & $\begin{array}{c}\text { No. } \\
\text { (male/female) }\end{array}$ & Treatment & Histology & Intent & Stage & $\begin{array}{l}\text { Cut-off } \\
\text { value }\end{array}$ & $\mathrm{HR}$ & Study type \\
\hline Dutta et al. (4) & 2012 & UK & 75 & $112(85 / 27)$ & $S^{1}$ & SCC, ADC & Cur & I-IV & 150,300 & $U$ & Uni/Re \\
\hline Yuan et al. (6) & 2014 & China & $63.1 \pm 9.7$ & $327(282 / 45)$ & $S^{1}$ & $A D C$ & Cur & I-IV & 150,300 & $U$ & Uni/Re \\
\hline Wan et al. (9) & 2016 & China & 63.0 & $179(150 / 29)$ & CRT & SCC, ADC & Cur & I-III & 180 & $U$ & Uni/Re \\
\hline Xie et al. (10) & 2016 & China & 58.1 & $317(244 / 73)$ & $S^{2}$ & ScC & Cur & I-III & 103 & U/M & Uni/Re \\
\hline
\end{tabular}

$\mathrm{S}$, surgery; $\mathrm{S}^{1}$, surgery \pm neo chemo-radiotherapy; CRT, chemo-radiotherapy; $\mathrm{S}^{2}$, surgery \pm adjuvant chemo-radiotherapy; SCC, squamous cell carcinoma; ADC, adenocarcinoma; Cur, curative intent; HR, hazard ratio; Uni, unicentric; Re, retrospective; U, univariate analysis; M, multivariate analysis.

\section{Acknowledgements}

None.

\section{Footnote}

Conflicts of Interest: The authors have no conflicts of interest to declare.

\section{References}

1. Deng J, Zhang P, Sun Y, et al. Prognostic and clinicopathological significance of platelet to lymphocyte ratio in esophageal cancer: a meta-analysis. J Thorac Dis 2018;10:1522-31.

2. Higgins JP, Altman DG. Assessing risk of bias in included studies. Cochrane Handbook for Systematic Reviews of Interventions. 2008:187-241.

3. Lorenc T, Felix L, Petticrew M, et al. Meta-analysis, complexity, and heterogeneity: a qualitative interview study of researchers' methodological values and practices. Syst Rev 2016;5:192.

4. Dutta S, Crumley AB, Fullarton GM, et al. Comparison of the prognostic value of tumour and patient related factors in patients undergoing potentially curative resection of gastric cancer. Am J Surg 2012;204:294-9.

5. Noble F, Hopkins J, Curtis N, et al. The role of systemic inflammatory and nutritional blood-borne markers in predicting response to neoadjuvant chemotherapy and survival in oesophagogastric cancer. Med Oncol 2013;30:596.

6. Yuan D, Zhu K, Li K, et al. The preoperative neutrophil-lymphocyte ratio predicts recurrence and survival among patients undergoing R0 resections of adenocarcinomas of the esophagogastric junction. J Surg Oncol 2014;110:333-40.

7. Liu JS, Huang Y, Yang X, et al. A nomogram to predict prognostic values of various inflammatory biomarkers in patients with esophageal squamous cell carcinoma. Am J Cancer Res 2015;5:2180-9.

8. Chen PC, Feng JF. A Novel Inflammation-Based Stage (I Stage) in Patients with Resectable Esophageal Squamous Cell Carcinoma. Mediators Inflamm 2016;2016:5396747.

9. Wan GX, Chen P, Cai XJ, et al. Elevated red cell distribution width contributes to a poor prognosis in patients with esophageal carcinoma. Clin Chim Acta 2016;452:199-203.

10. Xie X, Luo KJ, Hu Y, et al. Prognostic value of preoperative platelet-lymphocyte and neutrophillymphocyte ratio in patients undergoing surgery for esophageal squamous cell cancer. Dis Esophagus 2016;29:79-85.

Cite this article as: Athanasiou A, Spartalis M, Spartalis E. Platelets-to-lymphocyte ratio and esophageal cancer. J Thorac Dis 2018;10(8):E650-E651. doi: 10.21037/jtd.2018.07.41 